This item was submitted to Loughborough's Research Repository by the author.

Items in Figshare are protected by copyright, with all rights reserved, unless otherwise indicated.

\title{
Plus size and obese workers: Anthropometry estimates to promote inclusive design
}

PLEASE CITE THE PUBLISHED VERSION

https://doi.org/10.1080/00140139.2019.1622791

\section{PUBLISHER}

Taylor and Francis

VERSION

AM (Accepted Manuscript)

\section{PUBLISHER STATEMENT}

This is an Accepted Manuscript of an article published by Taylor \& Francis in Ergonomics on 12 June 2019, available online: http://www.tandfonline.com/10.1080/00140139.2019.1622791.

\section{LICENCE}

CC BY-NC-ND 4.0

\section{REPOSITORY RECORD}

Gyi, Diane, Annabel E. Masson, and Sue Hignett. 2019. "Plus Size and Obese Workers: Anthropometry Estimates to Promote Inclusive Design”. Loughborough University. https://hdl.handle.net/2134/37880. 


\section{Ergonomics}

\section{Plus size and obese workers: Anthropometry estimates to promote inclusive design}

\section{Diane Gyi, Annabel Masson \& Sue Hignett}

To cite this article: Diane Gyi, Annabel Masson \& Sue Hignett (2019): Plus size and obese workers: Anthropometry estimates to promote inclusive design, Ergonomics, DOI: 10.1080/00140139.2019.1622791

To link to this article: https://doi.org/10.1080/00140139.2019.1622791

Accepted author version posted online: 27 May 2019.

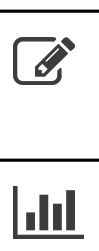

Submit your article to this journal $ک \pi$

Ill Article views: 3

View Crossmark data $₫$ 


\section{Plus size and obese workers: Anthropometry estimates to promote inclusive design}

\section{Diane Gyi}

Loughborough Design School, Loughborough University, Loughborough, UK ORCID 0000-0002-7755-1244

LinkedIn: https://www.linkedin.com/in/diane-gyi-1a65331/

Annabel Masson Footnote

Loughborough Design School, Loughborough University, Loughborough, UK

LinkedIn: https://www.linkedin.com/in/annabel-masson-69908686/

Footnote: School of Sport, Exercise and Rehabilitation Sciences, University of Birmingham, UK

\section{Sue Hignett}

Loughborough Design School, Loughborough University, Loughborough, UK ORCID: 0000-0002-3025-7451

LinkedIn: https://www.linkedin.com/in/sue-hignett-6763208/

Corresponding author:

Dr Diane Gyi

Loughborough Design School,

Loughborough University

Loughborough

Leicestershire, LE11 3TU

Email: d.e.gyi@lboro.ac.uk

Telephone: +44 (1509 223043 


\title{
Plus size and obese workers: Anthropometry estimates to promote inclusive design
}

\begin{abstract}
A significant proportion of the adult population globally is overweight, obese or classed as 'plus size'. This has led to variability in size and shape across the working population and exclusion in the workplace. A new dataset of the anthropometry of plus size people has been created. Length dimensions were similar to other data, but breadth, circumference, and depth measurements were substantially larger. Hip breadth and abdominal depth were important for predicting largeness in this population. These data help explain the high exclusion rates from design and the number of fit, reach, posture and clearance issues reported by participants with a high BMI: generally, the higher the BMI the greater prevalence of problems. It is hoped that a better understanding of the anthropometric characteristics of the plus size worker will inform the design of safe, productive work environments to promote inclusion for a wider range of people.
\end{abstract}

Keywords: anthropometry; workplace design; obesity; overweight; architectural design

Subject classification codes: include these here if the journal requires them

Word count: 3879

\section{Practitioner summary}

A new anthropometry dataset of plus size people has been created. The higher the BMI the greater the problems with design in the workplace for fit, reach, posture and clearance. To ensure inclusion and reduce stigma it is important to understand more about the size and shape of this population. 


\section{Introduction}

It is widely acknowledged that a large proportion of the global adult population are now overweight, obese, or classed as plus size. A recent House of Commons briefing paper (Baker, 2018) provided overweight (BMI between 25.0 - $29.9 \mathrm{~kg} / \mathrm{m}^{2}$ ) and obesity (BMI over $30.0 \mathrm{~kg} / \mathrm{m}^{2}$ ) estimates from surveys for England, Wales and Scotland as $61.4 \%$, $59 \%$ and $65 \%$ respectively: with the UK having the sixth highest rate of obesity after the USA, Mexico, New Zealand, Hungary and Australia. Indeed, worldwide, the prevalence of obesity has nearly doubled in the period 1980-2008, and estimates in EU countries, show that overweight affects $30-70 \%$ and obesity affects $10-30 \%$ of adults (WHO, 2018).

In ergonomics and related fields, much research has been conducted concerning overweight/obese workers. Cavuoto and Nussbaum (2014) conducted a review of the impact of obesity on work-related tasks and concluded that larger anthropometric dimensions and the consequent adjustments needed in working postures are likely to significantly increase the biomechanical demands on the musculoskeletal system. Being plus size is associated with increased absence from work (Han et al. 2009), reduced productivity (Bhattachergee et al. 2003) and represents a major risk factor for premature job leave (Jusot et al. 2008). Indeed, obese manual materials handlers are likely to be at risk of developing a musculoskeletal disorder during lifting because of biomechanical stress on the back (e.g. Singh et al. 2015; Corbeil et al. 2019). In addition, pre-obese and obese individuals have a significantly lower range of motion than those of normal weight for elbow flexion, supination, hip extension and flexion, knee flexion and plantarflexion, which also has implications for manual handling at work (Jeong et al. 2018). In an experimental study by Park et al. (2009), obese participants reported significantly higher postural stress (than a non-obese group) when performing 84 typical 
static, whole-body working postures. These researchers advocate the need for proactive ergonomic design and creativity in problem solving to facilitate obesity-friendly work environments. Interestingly, obesity does not appear to reduce maximum acceptable weight in lifting tasks (Singh et al. 2009). Finally, obesity in workers has also been associated with a high rate of slip, trip and fall injuries in the workplace compared with those of a healthy weight (Koepp et al. 2015). Obesity also has an adverse effect on postural stability when performing work tasks; anterior-posterior sway was significantly larger for obese workers than those of normal weight whilst performing assembly work tasks (Hamilton et al. 2015).

Issues associated with plus size workers are of concern, as increasing employment, supporting people into work, and maintaining people at work are key elements of the UK Government public health and welfare reform agendas (Department for Work and Pensions, 2008). There are also economic, social and moral arguments that work is the most effective way to improve well-being and a strong evidence base that work is generally good for physical and mental health (Burton and Waddell, 2006). Engaging in work activities is also part of a life-course approach to preventing and managing overweight or obesity.

Physical barriers to inclusivity can be defined as a form of stigma (Lewis et al. 2011) so there is an increasing need to consider the emotional and social aspects of plus size people's interactions with design. The inherent visibility of 'plus size' makes it a sensitive topic that is influenced by the social context of where user interactions take place. The design of the environment also seems to contribute to the stress experienced by people who feel stigmatized directly or indirectly because of their weight (Brewis, 2014). In a small study by Koesten et al. (2016), plus size interviewees describe constantly needing to anticipate problems and plan different possibilities when 
confronted with products or environments that are uncomfortable or inaccessible. For example, at work seating was problematic, such as feeling unsafe and unstable, poor fit, tight access and difficulties getting on/off low furniture. The findings of this exploratory study suggest that consideration of the emotional responses to physical issues (e.g. guilt, embarrassment), is important, to encourage engagement of plus size people in work activities. Feeling different, induced by the design of the physical world (e.g. aircraft bathrooms, aisle width, seat belt size) perpetuates weight stigma and may have a negative effect on health outcomes.

The plus size epidemic has led to increased variability in size and shape across the working population. Dianat et al. (2018) highlight the lack of anthropometric data on specific user populations. Designers need access to specialist data to enable better design of the spaces where people live and work. Anthropometry is the science of human body measurements with individuals having unique body dimensions in different proportions that determine their body shape. There are several anthropometry data sets available to support the design process including BodySpace (Pheasant and Haslegrave, 2006), CAESAR (Robinette et al. 2002), Adultdata (Peebles and Norris, 1998) and Peoplesize (Open Ergonomics, 2008). However, the rapid increase in the prevalence of plus size people in the working population means that they are not fully represented in such datasets. Dianat et al. (2018) conducted a review of anthropometric data in ergonomics and product design and identified a gap between such data and its application. They advocate the need for anthropometric data on target-user populations and the need for datasets on populations of interest. Therefore, it is believed that there is an urgent need for anthropometric data to understand more about the physical size and shape of plus size people. This will enable design to be more inclusive and facilitate safe, comfortable and productive working environments reducing the risk of 
absenteeism and premature job leave. The aim of the research reported in this paper was to collect key anthropometric measurements of plus size people pertinent to design in the workplace such as fit, reach, posture and clearance.

\section{Method}

\section{Pilot study}

Collecting self-reported anthropometric data is an efficient way (in terms of cost and resources) of accessing large, geographically diverse and difficult to reach populations. A previous pilot study by the authors (Masson et al. 2015) indicated that selfmeasurement of plus size adults, was feasible and reliable. Anthropometric dimensions (Table 1) pertinent to design in the workplace e.g. seating, working space and uniforms, were selected for measurement. In brief, a sample of 20 plus size workers (10 males, 10 females) was recruited and the 14 'self-measured' anthropometric measurements were compared with researcher measurement. Knee splay (normally measured in pregnant women) was included as a new measurement to represent the observed seating position of plus size individuals (Sibella et a1. 2003) and is defined as the distance between the outer borders of the knees whilst seated (Acar and Weeks, 2006). In order to understand body shape, participants were presented with outline images and also asked to classify themselves as one of five shapes; straight, apple, cone, pear, hourglass (Connell et al. 2006). The measurement guide contained simplified instructions based on ISO (2015), Pheasant and Haslegrave (2006), and Peebles and Norris (1998). The guide also included annotated photographs using a plus size model: using real people rather than diagrams encourages engagement in research activities (National Institute for Health Research, 2009). 
Data analysis found that the two methods of measurement (self and researcher measured) agreed sufficiently closely for 11 of the 14 measurements, with significant differences ( $\mathrm{p} \geq 0.01)$ only found for weight $(\mathrm{p}=0.000)$ and stature $(\mathrm{p}=0.000)$. This pattern has been reported in previous studies, where weight was under-reported (e.g. Stommel et al. 2009) and stature was over-reported (e.g. DelPrete et al. 1992; Allison et al. 1999). Likely reasons for this include conscious under reporting due to social acceptance (Gorber et al. 2007) or inaccurate reporting due to avoiding measuring themselves (Stommel et al. 2009). For stature, discrepancies could also be due to clothing worn and order of measurements (Tokmakidis et al. 2012). There was also some disagreement between the participant and researcher in the classification of body shape, therefore this was noted for the main study.

\section{Sampling strategy}

Permission to conduct the study was granted by Loughborough University Ethical Advisory Committee. Various sampling techniques were considered but due to the sample being relatively unknown and potentially widely dispersed, a non-probability approach was taken using a combination of purposive and snowball sampling by contacting key individuals and placing links to the study on online forums. Inclusion criteria were: age 18 or over, either employed or self-employed (in the last 12 months), resident in the UK and self-classification as 'plus size' or larger than average.

\section{Measurement procedure}

Individuals who believed they met the inclusion criteria and were interested in participating in the study were directed to an online Self Measurement Guide via Survey Monkey which contained a full description (with photograph) of each of the 14 measurements to be taken (Table1). This was the same guide used in the pilot study and 
Figure 1 shows examples of the instructions given to participants. They were instructed to wear close fitting, indoor work clothing (but no jackets or bulky/padded items), empty all pockets and remove shoes. All measurements were to be taken with a tape measure: pilot work had indicated that measuring would take around 20 minutes. Participants were also advised to ask for help from a friend if possible. Background details were also collected i.e. gender, age, body shape, ethnic group, job details and specific problems with fit, reach and clearance.

\section{Results}

A total of 113 responses were received with 12 removed due to missing data (e.g. weight, stature) resulting in a sample size of 101 plus size workers (47 males and 54 females). There was a spread of age distribution: 18-24 (males 7\%, females 9\%); 25-44 (males 18\%, 24\%); 45-64 (males 22\%, females 21\%). Mean Body Mass Index (BMI) was $40.3 \mathrm{~kg} / \mathrm{m}^{2}$ (SD 8.4) for males and $43.5 \mathrm{~kg} / \mathrm{m}^{2}$ (SD 8.5) for females. With regard to body shape, by far the majority (44\% of females; $70 \%$ of males) classed themselves as apple shape, followed by hourglass $(28 \%)$ and pear in females $(24 \%)$, and straight in males $(26 \%)$.

\section{The workplace}

The majority of participants came from the healthcare sector (19\%), followed by hospitality (18\%), retail (15\%), transport (15\%), education (9\%), public services $(9 \%)$, construction (8\%), financial (5\%) and legal (3\%). With regard to design in the workplace, all participants indicated some issues: fit of seating (81\%) and uniforms $(62 \%)$; inadequate toilet cubicle size (73\%); clearance and space to move around the immediate working area (62\%), shared spaces e.g. cafes, meeting rooms (49\%) and stairways or corridors (43\%); and the height of working surfaces (59\%) affecting 
posture and reach. Generally, the higher the BMI the greater the prevalence of problems. For example, the majority of participants (71\%) with a BMI $30-34.9 \mathrm{~kg} / \mathrm{m}^{2}$ reported problems with seat size, with all participants with a BMI over $50 \mathrm{~kg} / \mathrm{m}^{2}$ indicating difficulties.

\section{Anthropometric data}

The mean and standard deviation of the 14 measurements for males and females were calculated (Table 2). Although the dataset was never intended to be representative, it was of interest to understand the normality of the distribution of scores for each measurement and any significant skew. The Kolmogorov-Smirnov statistic was therefore calculated for each measurement. The scores for males for chest, stomach and hip circumference, shoulder breadth, forward fingertip reach and abdominal depth, were all not significant $(\mathrm{p} \geq 0.05)$ indicating a normal distribution, and for females, scores for stature, hip circumference, thigh depth and popliteal height indicated normality. Further analysis of the distribution of all 14 measurements was performed using Normal Q-Q graphs and a level of agreement was found between the observed value for all measurements for males and females (including those that had not statistically shown normality) when plotted against the expected value from the normal distribution, indicating a degree of confidence in the data.

Correlations between the 14 measurements were explored using Pearson product-moment correlation coefficient ( $\mathrm{r}$ value). For males, the strongest correlations $(\mathrm{p} \leq 0.01)$ were between; abdominal depth and hip breadth $(\mathrm{r}=0.77)$, hip breadth and knee splay $(r=0.77)$ and hip breadth and buttock to front of knee $(r=0.75)$. Chest circumference and hip circumference were also strongly correlated $(r=0.72)$. Hip breadth, weight and knee splay showed strong associations with the highest proportion of other variables for male participants. For females, the strongest correlations $(p \leq 0.01)$ 
were between; weight and abdominal depth $(\mathrm{r}=0.77)$, chest circumference and hip circumference $(\mathrm{r}=0.74)$, abdominal depth and knee splay $(\mathrm{r}=0.71)$ and hip breadth and shoulder breadth $(\mathrm{r}=0.70)$. Abdominal depth, chest circumference and knee splay showed strong associations with the highest proportion of other variables. For both males and females respectively, weight, was strongly and significantly $(p \leq 0.01)$ correlated with all three circumference measurements of chest ( $r=0.61, r=0.69)$, waist $(\mathrm{r}=0.62, \mathrm{r}=0.61)$, and hip $(\mathrm{r}=0.61,0.67)$ and breadth measurements of hip breadth $(\mathrm{r}=0.64, \mathrm{r}=0.59)$ and knee splay $(\mathrm{r}=0.59, \mathrm{r}=0.59)$.

For each of the positive and significant correlations, the coefficient of determination was calculated $\left(\mathrm{r}^{2}\right)$ to understand the shared variance or degree of overlap between the measurements. For males, just over half of the variation in hip breadth can be explained by buttock to front of knee length $\left(r^{2}=0.56\right)$, knee splay $\left(r^{2}=0.59\right)$ and abdominal depth $\left(r^{2}=0.59\right)$. Chest circumference and hip circumference also had over $50 \%$ of shared variance $\left(r^{2}=0.52\right)$. For females, over half of the variation in abdominal depth could be explained by weight $\left(r^{2}=0.59\right)$, and knee splay $\left(r^{2}=0.50\right)$ measurements. Similar to males, chest circumference and hip circumference in females also had over $50 \%$ of shared variance $\left(\mathrm{r}^{2}=0.56\right)$.

\section{Comparison with existing data}

The mean for each of the measurements was compared with data for UK Adults, from anthropometry resources frequently used by design teams (Pheasant and Haslegrave, 2006; Peebles and Norris, 1998). For males, seven measurements were substantially larger and for females, eight were larger than this dataset (Table 4) with the measurements for abdominal depth and thigh depth nearly double for both males and females. Although it is not possible to compare knee splay with this dataset, as it is a novel measurement for this population, it should be noted that it is considerably larger 
than both hip breadth and shoulder breadth for both males and females with implications for design in the workplace.

It is also of interest to consider the percentage of the study population who would potentially be excluded if designing to include up to $95^{\text {th }}$ percentile British adults using data from these datasets. For example, Table 5 shows that more than $90 \%$ of the sample would be excluded if designing for optimal fit (e.g. seating, toilet cubicles) or clearance was based on measurements such as abdominal depth, hip breadth, thigh depth, shoulder breadth from 'normal' datasets. Current circumference estimates (chest, hip and waist) needed for uniform sizing are also likely to be problematic.

\section{Discussion}

The new dataset clearly shows that plus size people are larger for circumference, breadth and depth measurements and these tend to reflect volumetric body size (Annis, 1996). Mean abdominal depth and mean thigh depth showed the largest proportional differences with existing datasets. Park and Park (2013) reported that largeness in the abdominal area is a feature of plus size body shapes, but thigh depth has not been reported. Weekes (2010) described the 'spread effect' in the seated posture of pregnant women: in sitting the abdomen cannot take its natural shape under the influence of gravity as it is limited by the upper thighs which exert pressure pushing it upwards and outwards. It is likely that a similar process is occurring for plus size people and that increased thigh depth will exacerbate this effect.

Length measurements (e.g. height, sitting shoulder height) were similar to existing data. It is interesting that forward fingertip reach was smaller for this plus size population and indeed other studies have reported reduced reach in this population to accommodate increased size. For example, Hamilton et al. (2013) found that a high 
BMI had an impact on maximum reach during small parts assembly work as they stood further away from the workstations to accommodate a larger abdominal depth.

Correlation analysis identified strong and significant relationships between anthropometric variables. For males, hip breadth was strongly correlated $(p \leq 0.01)$ with abdominal depth, knee splay, and buttock to front of knee length. This suggests that hip breadth may be a useful measure for forecasting the magnitude of these other measurements.

The relationship between weight and thigh depth was also strong. For females, abdominal depth was strongly correlated $(\mathrm{p} \leq 0.01)$ with weight, knee splay, chest circumference, hip circumference, waist circumference, hip breadth and buttock to front of knee length. For both males and females, weight, was strongly and significantly $(\mathrm{p} \leq 0.01)$ correlated with all three circumference measurements, chest, waist, and hip, and breadth measurements of hip breadth and knee splay. These data suggests that an increase in weight does not relate to just one anatomical area but can affect measurements of circumference, depth and breadth in the torso and lower body. The dearth of literature exploring the anthropometric characteristics of plus size people makes comparing the findings of this study with others difficult. Although Park and Park (2013) note that apple and pear body shapes are most frequently reported in the plus size literature, it is likely that simplistic descriptions of plus size body shapes may be unrepresentative of the current plus size working population.

All participants in this study self-classified themselves as plus size or larger than average (supported by their BMI), but there are implications for profiling the plus size body shape. The diversity of the plus size shape across the study population was apparent in the percentage of variance shared by pairs of anthropometric measurements. For males, just over half of the variation for abdominal depth, buttock to front of knee 
and knee splay dimensions can be explained by hip breadth. Similarly, for females, abdominal depth accounts for half of the variation for weight and knee splay. The distribution of body fat (location and magnitude) may help to explain this variability in body shape both between and within gender. This is a view supported by Park and Park, (2013) who identified eight body types (including 'large everywhere', small torso and large lower body' and 'large torso surface') for Korean plus size individuals.

As in previous studies by the authors (Masson et al. 2014; Koesten et al. 2016), a high proportion of the study population reported issues relating to fit, reach, posture and clearance in the work place. Many obese workers will need to stand or sit further from their work area requiring extended reaching and increased biomechanical load. Seat size was the biggest concern and this not surprising as anthropometric data is paramount to good seating design (Deros et al, 2015; Pheasant and Haslegrave, 2006). In addition, in a study of office workers, Benden et al. (2011) found that the more overweight a person was, the more likely they were to spend the day seated. It may be that workplace stigma (Koester et al. 2016), fatigue (Benden, 2008) and functional limitations (Sibella et al. 2003) are contributory factors. The likely explanation for plus size people having difficulties interacting with the physical environment at work, is that anthropometry estimates are often based on an average user (Perry, 2010; Menegoni et al. 2009) and any mismatches will result in dissatisfaction (Brewis, 2014). These results also identified that individuals with BMI of $35 \mathrm{~kg} / \mathrm{m}^{2}$ and above experience more issues in the working environment. Indeed, reduced forward functional reach was also found for high BMI individuals in a study of small parts assembly workers (Hamilton et al. 2013). The functional limitations of this group need more exploration as they are likely to impact on safety, comfort and performance as well as affecting emotional and social behaviour. 
The use of self-measurement in previous research has been limited primarily to the measures of stature, weight and waist circumference. The self-measurement guide has enabled the collection of 14 anthropometric measures applicable to workplace design. This approach has been shown to be acceptable to the target population, resource lean and suitable for 'hard to reach' populations.

A limitation of this study is the sample size: although it was appropriate in terms of age and gender spread, it fell short of a statistical power formula proposed in ISO 15535 (2012), which suggests that for establishing an anthropometric database with the required level of accuracy a sample size of 300 is needed. However, it was not an objective of the study to create a representative database. Random or stratified sampling techniques were considered but due to the relatively unknown population and the anticipated difficulty in recruiting participants they were not deemed appropriate. The anthropometric data of the plus size working age people collected in this study were not normally distributed for all measurements, although Normal Q-Q graphs showed a level of agreement between the observed and predicted values indicating a degree of confidence in the data. Although the questionnaire element helped understand some of the issues experienced by plus size people in the working environment, more depth would have provided greater insight and knowledge to support stakeholders. However, increasing the length of the questionnaire would have substantially increased the time taken to complete the study impacting on response rate (Robson, 2011). Finally, the self-reported body shape data (e.g. apple, pear, hourglass) should be treated with some caution, as in the pilot study there was some disagreement between participant and researcher classification. In any case, the findings of this research support the view that simplistic descriptions of plus size body shapes are unlikely to be possible. 


\section{Conclusions}

A new dataset of the anthropometry of plus size people has been created. This research has answered an urgent need to understand more about the physical size and shape of plus size people to facilitate more inclusive design in the workplace. Existing datasets for equipment, workspace, environment and architectural design were found to lack information to ensure inclusion and reduce the stigma felt by plus size people in the workplace. In addition, Cavuoto and Nussbaum (2014) advocate that understanding the consequences of obesity is critical, as guidelines and tools for the evaluation and prevention of MSDs are primarily based on normal-weight individuals.

The anthropometric data collected have enabled a better understanding of the size and shape of the plus size population in terms of variability and predictors of largeness. The findings support the following conclusions:

- Plus size people are clearly considerably larger, but not in all dimensions. Length measurements remain similar to existing datasets, but measurements of breadth, circumference and depth are substantially increased.

- Hip breadth may be a useful measure for predicting the magnitude of other anthropometric measurements in males. Abdominal depth is useful for predicting largeness in females.

- Design in the workplace was reported to be inadequate leading to an urgent need for proactive ergonomic design to facilitate more inclusive work environments. Seating was found to be most problematic, followed by toilet cubicle size and working spaces. Individuals with a very high BMI $\left(35 \mathrm{~kg} / \mathrm{m}^{2}\right.$ and over) reported more issues. 
- Knee splay was substantially larger than measurements for hip and shoulder breadth. Given the functional relevance of this measurement, consideration should be given to using it to determine space and clearance requirements.

- There is variability in the plus size body shape both within and between gender due to distribution of body fat (location and magnitude) affecting anthropometric dimensions. This needs further exploration.

- Finally, self-measurement of anthropometric dimensions is a reliable and costeffective way of collecting data on difficult to access populations.

\section{Acknowledgements}

We would like to express our gratitude to the individuals and organisations who spared their valuable time to participate in the project.

\section{References}

Acar, B.S., and A.M. Weekes, 2006. Measurements for pregnant drivers' comfort and safety. International Journal of Vehicle Design 42(1): 101-118.

Allison, D., R. Fontaine, M. Heo. J. Mentore, J. Cappelleri, L. Chandler, P. Weiden, and L. Cheskin, 1999. The Distribution of Body Mass Index among Individuals with and without Schizophrenia. Journal of Clinical Psychiatry 60(4): 215-220.

Annis, J., 1996. Ageing effects on anthropometric dimensions important to workplace design. International Journal of Industrial Ergonomics 18(5-6): 381-388.

Baker, C., 2018. Obesity Statistics. Briefing Paper, Number 3336, 20 March 2018. House of Commons Library. Accessed March 5, 2019. http://researchbriefings.files.parliament.uk/documents/SN03336/SN03336.pdf.

Benden, M., 2008. Could you stand to lose: weight loss secrets for office workers. 2nd ed. Dallas, Texas: Trinity River Publishing. 
Benden, M., R. Fink, and J. Congleton, 2011. An in-situ study of the habits of users that affect office chair design and testing. Human Factors 53(1): 38-49.

Bhattacherjee, A., N. Chau, C. Sierra, B. Legras, L. Benamghar, and J. Michaely, 2003. Relationship of job and some individual characteristics to occupational injuries in employed people: a community based study. Journal of Occupational Health 45(6): 382-391.

Brewis, A.A., 2014. Stigma and the perpetuation of obesity. Social Science and Medicine 118: 152-158.

Burton, K. and G. Waddell, 2006. Is Work Good for your Health? London: The Stationary Office.

Connell, L., P. Ulrich, E. Brannon, M. Alexander, and A. Presley, 2006. Body shape assessment scale: Instrument development for analysing female figures. Clothing and Textiles Research Journal 24(2): 80-95.

Corbeil, P., A. Plamondon, G. Handrigan, J. Vallee-Marcotte, S. Laurendeau, J. Ten Have, and N. Mazerolle, 2019. Biomechanical analysis of manual material handling movement in healthy weight and obese workers. Applied Ergonomics 74(1): 124-133.

Cavuoto, L., and M. Nussbaum, 2014. Influences of obesity on job demands and worker capacity. Current Obesity Reports 3: 341-347.

DelPrete. L., M. Caldwell, C. English, S. Banspach, and C. Lefebvre, 1992. Selfreported and measured weights and heights of participants in community-based weight loss programs. Journal of American Dietetic Association 92(12): 14831496. 
Deros, B., D. Daruis, and M. Nor, 2015. Incorporating Malaysian's Population Anthropometry Data in the Design of an Ergonomic Driver's Seat. Procedia Social and Behavioural Sciences 195: 2753-2760.

Department for Work and Pensions, 2008. Improving health and work and changing lives. Accessed March 5, 2019. https://www.gov.uk/government/publications/improving-health-and-workchanging-lives.

Dianat, I., J. Molenbroek, and H.I. Castellucci, 2018. A review of the methodology and applications of anthropometry in ergonomics and product design. Ergonomics. doi: 10.1080/00140139.2018.1502817.

Gorber, S., M. Tremblay, D. Moher, and B. Gorber, 2007. A Comparison of Direct vs. Self-report Measures for Assessing Height, Weight and Body Mass Index: A Systematic Review. Obesity Reviews 8: 307-326.

Han, E. E. Norton, and S. Stearns, 2009. Weight and wages: fat versus lean pay checks. Health Economics 18(5): 535-48.

Hamilton, M., L. Strawderman, K. Babski-Reeves, and B. Hale, 2013. Effects of BMI and task parameters on joint angles during simulated small parts assembly. International Journal of Industrial Ergonomics, 43: 417-424.

Hamilton, M., L. Strawderman, B. Hale, and K. Babski-Reeves, 2015. Effects of BMI and task parameters on postural sway during simulated small parts assembly. Ergonomics 58(3): 504-512.

ISO:15535, 2012. General Requirements for Establishing Anthropometric Databases. International Standardisation Organisation.

ISO:7250, 2015. Basic Human Body Measurements for Technical Design. International Standardisation Organisation. 
Jusot, F., M. Khlat, T. Rochereau, and C. Serme, 2008. Job loss from poor health, smoking and obesity: a national prospective survey in France. Journal of Epidemiology and Community Health 62(4): 332-337.

Jeong, Y., S. Heo, L. Giwhyun, and W. Park, 2018. Pre-obesity and obesity impacts on passive range of motion. Ergonomics, 61(9): 1223-1231. Doi: 10.1080/00140139.2018.1478455.

Koepp, G.A., B.J. Snedden, and J.A. Levine, 2015. Workplace slip, trip and fall injuries and obesity. Ergonomics 58(5), 674-679.

Koesten, L., D. Gyi, A. Masson, and P. Jordan, 2016. Plus size and inclusivity in design. Paper presented at the Chartered Institute of Ergonomics and Human Factors Conference, Daventry, April 19-21.

Lewis, S., S.L. Thomas, R.W. Blood, D.J. Castle, J. Hyde, and P.A. Komesaroff, 2011. How do obese individuals perceive and respond to different types of obesity stigma they encounter in their daily lives? A qualitative study. Social Science and Medicine 73: 1349-1356.

Masson, A., S. Hignett, and D, Gyi, 2014. Exploring and describing workplace issues for plus size people. Paper presented at the 3rd International Conference on Ergonomics Modelling, Usability \& Special Populations / 5th International Conference on Applied Human Factors and Ergonomics, Krakow, July 21- 25.

Masson, A., S. Hignett, and D. Gyi, 2015. Anthropometric study to understand body size and shape for plus size people at work. Procedia Manufacturing 3: 56475654.

Menegoni, F. G., Manuela, E., Tacchini, L., Vismara, M., Cavigioli, P., and Capodaglio, 2009. Gender-specific Effect of Obesity on Balance. Obesity 17(10): 1951-1960. 
National Institute for Health Research (NIHR), 2009. Exploring Impact: Public involvement in NHS, public health and social care research. Accessed March 5 2019. https://www.invo.org.uk.

Open Ergonomics (2008). Peoplesize. Accessed March 5, 2019.

https//:www.openerg.com.

Park, W., and S. Park, 2013. Body shape analyses of large persons in South Korea. Ergonomics 46(4): 692-706.

Park, W., D. Singh, M. Levy, and E. Jung, 2009. Obesity effect on perceived postural stress during static posture maintenance tasks. Ergonomics 52(9): 1169-1182.

Peebles, L., and B. Norris, 1998. Adultdata: The handbook of Adult Anthropometric and Strength Measurements- Data for Design Safety. London: Department of Trade and Industry.

Perry, L.S., 2010. The Aging Workforce: Using Ergonomics to Improve Workplace Design. Professional Safety: Journal of the American Society of Safety Engineers 55: 22-28.

Pheasant, S., and C. Haslegrave, 2006. Bodyspace: Anthropometry, Ergonomics and the Design of Work. $3^{\text {rd }}$ edition. Florida: Taylor and Francis.

Robinette, K.M., H. Blackwell, M. Daanen, M. Boehmer, and S. Fleming, 2002. Civilian American and European Surface Anthropometry Resource (CAESAR), Final Report, Vol.1 Summary. Defence Technical Information Centre. https://apps.dtic.mil/docs/citations/ADA406704

Robson, C., 2011. Real World Research. $3^{\text {rd }}$ Edition. West Sussex: John Wiley and Sons.

Sibella, F., M. Galli, and E. Tacchini, 2003. Biomechanical analysis of sit to stand movement in normal and obese subjects. Clinical Biomechanics 18(8): 745-750. 
Singh, D., W. Park, D. Hwang, and M. Levy, 2015. Severe obesity effect on low back biomechanical stress of manual handling load lifting. Work 51(2): 337-348.

Singh, D., W. Park, and M. Levy, 2009. Obesity does not reduce maximum acceptable weights of lift. Applied Ergonomics 40(1): 1-7.

Stommel, M., and C. Schoenborn, 2009. Accuracy and usefulness of BMI measures based on self-reported weight and height: findings from the NHANES \& NHIS 2001-2006. BMC Public Health 9: 421-427.

Tokmakidis, S., A. Christodoulos, and H. Douda, 2012. ed. Self-reported Anthropometry: body mass index and body composition. In Handbook of Anthropometry, edited by V.R. Preedy, 167-183. New York: Springer.

Weekes, A.M., 2010. Testing to Investigate the Use of Lap Belt Positioners During Pregnancy. Paper presented at the American Society of Mechanical Engineers10th Biennial Conference on Engineering Systems Design and Analysis, Istanbul, July 12-14.

World Health Organisation (WHO), 2018. Health topics. Data and statistics. Accessed March 5, 2019. http://www.euro.who.int/en/health-topics/noncommunicablediseases/obesity/data-and-statistics. 
Table 1. Anthropometric measurements taken.

Anthropometric measurement

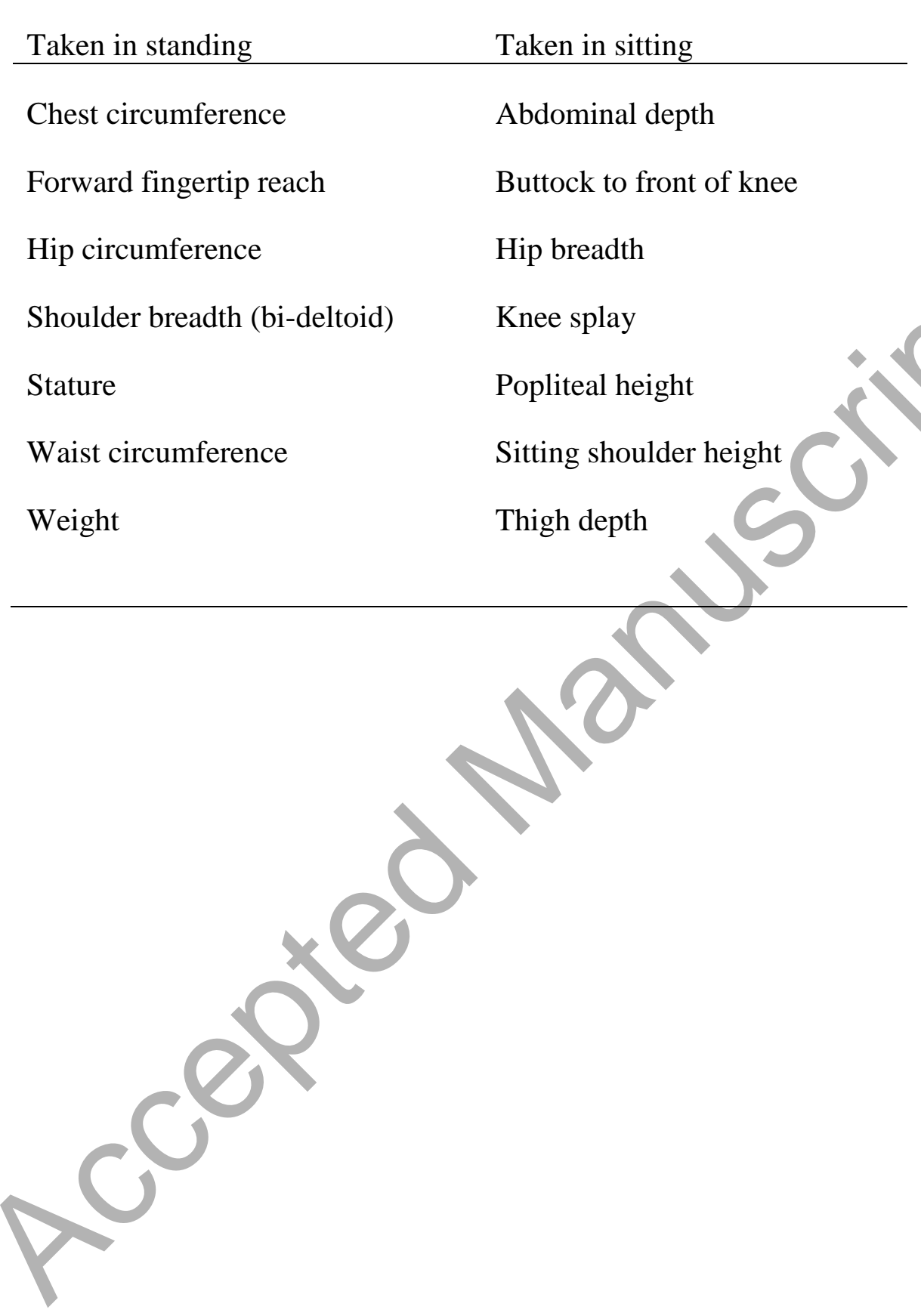


Table 2. Descriptive statistics for anthropometric measurements $(n=101)$

\begin{tabular}{|c|c|c|c|c|}
\hline \multirow{2}{*}{$\begin{array}{l}\text { Anthropometric } \\
\text { measurement }(\mathrm{mm})\end{array}$} & \multicolumn{2}{|l|}{ Males $(n=47)$} & \multicolumn{2}{|l|}{$\begin{array}{l}\text { Females } \\
(\mathrm{n}=54)\end{array}$} \\
\hline & Mean (SD) & Range & Mean (SD) & Range \\
\hline Abdominal depth & $537(113)^{*}$ & $280-840$ & $498(111)+$ & $320-890$ \\
\hline $\begin{array}{l}\text { Buttock to front of } \\
\text { knee }\end{array}$ & $633(70)+$ & $540-880$ & $618(69)+$ & $490-850$ \\
\hline Chest circumference & $1341(130)^{*}$ & $1100-1650$ & $1303(149)+$ & $1000-1700$ \\
\hline Forward fingertip reach & $812(55)^{*}$ & $720-1000$ & 735 (80)\# & $450-920$ \\
\hline Hip breadth & $590(109)+$ & $390-880$ & $609(113)+$ & $460-960$ \\
\hline Hip circumference & $1296(157)^{*}$ & $990-1650$ & $1345(162)^{*}$ & $1060-2000$ \\
\hline Knee splay & $588(71)+$ & $460-770$ & $577(89)+$ & $450-820$ \\
\hline Popliteal height & $453(53)+$ & $390-570$ & $386(34)^{*}$ & $320-500$ \\
\hline Thigh depth & $334(59)+$ & $230-460$ & $310(70)^{*}$ & $190-450$ \\
\hline $\begin{array}{l}\text { Shoulder breadth } \\
\text { (deltoid) }\end{array}$ & $570(104)^{*}$ & $420-760$ & $537(90)+$ & \\
\hline Sitting shoulder height & $634(59)+$ & $540-770$ & $592(80)+$ & $490-970$ \\
\hline Stature & 1752 (62)\# & $1560-1860$ & $1604(86)^{*}$ & $1430-1800$ \\
\hline Waist circumference & $1375(134)^{*}$ & $1110-1760$ & $1308(137)+$ & $970-1620$ \\
\hline Weight (kg) & $125(27)+$ & $93-207$ & $113(24)+$ & $88-200$ \\
\hline
\end{tabular}

$\mathrm{SD}=$ Standard Deviation

$*=$ A normal distribution indicated - Kolmogorov-Smirnov statistic not significant

$(\mathrm{p} \geq 0.05)$

$+=$ Violation of normality - slight positive skew

\#=Violation of normality - slight negative skew 
Table 3. Comparison of mean value between plus size data set $(\mathrm{n}=101)$ and British Adults Aged 19-65 (Pheasant and Haslegrave, 2006).

\begin{tabular}{|c|c|c|c|c|c|c|}
\hline \multirow{2}{*}{$\begin{array}{l}\text { Anthropometric } \\
\text { measurement } \\
(\mathrm{mm})\end{array}$} & \multicolumn{3}{|l|}{ Males } & \multicolumn{3}{|l|}{ Females } \\
\hline & $\begin{array}{l}\text { Plus size } \\
\text { mean }\end{array}$ & $\begin{array}{l}\text { British } \\
\text { Adults }\end{array}$ & Difference & $\begin{array}{l}\text { Plus size } \\
\text { mean }\end{array}$ & $\begin{array}{l}\text { British } \\
\text { Adults }\end{array}$ & Difference \\
\hline Abdominal depth & 537 & 270 & +267 & 498 & 255 & +243 \\
\hline $\begin{array}{l}\text { Buttock to front of } \\
\text { knee }\end{array}$ & 633 & 595 & +38 & 618 & 570 & +48 \\
\hline Chest circumference & & & N/A & & & N/A \\
\hline $\begin{array}{l}\text { Forward fingertip } \\
\text { reach }\end{array}$ & 812 & $906^{*}$ & -92 & 735 & $808 *$ & -73 \\
\hline Hip breadth & 590 & 360 & +230 & 609 & 370 & 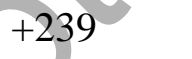 \\
\hline Hip circumference & 1296 & $1047 *$ & +249 & 1345 & & $3 \cap 0$ \\
\hline Knee splay & & & N/A & & & \\
\hline Popliteal height & 453 & 440 & +13 & 386 & 400 & -14 \\
\hline Thigh depth & 334 & 160 & +174 & 310 & 155 & +155 \\
\hline $\begin{array}{l}\text { Shoulder breadth (bi- } \\
\text { deltoid) }\end{array}$ & 570 & 465 & +105 & & 395 & +142 \\
\hline $\begin{array}{l}\text { Sitting shoulder } \\
\text { height }\end{array}$ & 634 & 595 & +39 & & 555 & +37 \\
\hline Stature & 1752 & 1740 & +12 & 1604 & 1610 & -6 \\
\hline Waist circumference & 1375 & $985^{*}$ & +390 & 1308 & $841 *$ & +467 \\
\hline Weight $(\mathrm{kg})$ & 125 & 75 & +50 & 113 & 63 & +50 \\
\hline
\end{tabular}


Table 4. Exclusion rates (\%) of the plus size sample who may be excluded from design that accommodates up to $95^{\text {th }}$ percentile British adults (Pheasant and Haslegrave, 2006)

\begin{tabular}{lll} 
Measurement & Males & Females \\
\hline Abdominal depth & $96 \%$ & $100 \%$ \\
Chest circumference & $82 \% *$ & $79 \% *$ \\
Hip breadth & $99 \%$ & $100 \%$ \\
Hip circumference & $98 \% *$ & $92 \% *$ \\
Thigh depth & $100 \%$ & $100 \%$ \\
Shoulder breadth & $64 \%$ & $92 \%$ \\
Waist circumference & $95 \% *$ & $100 \% *$ \\
Weight & $97 \%$ & $100 \%$ \\
\hline$*=$ compared with $95^{\text {th }}$ percentile value from Adultdata (Peebles and Norris, 19
\end{tabular}


Figure 1. Example from the Self-Measurement Guide

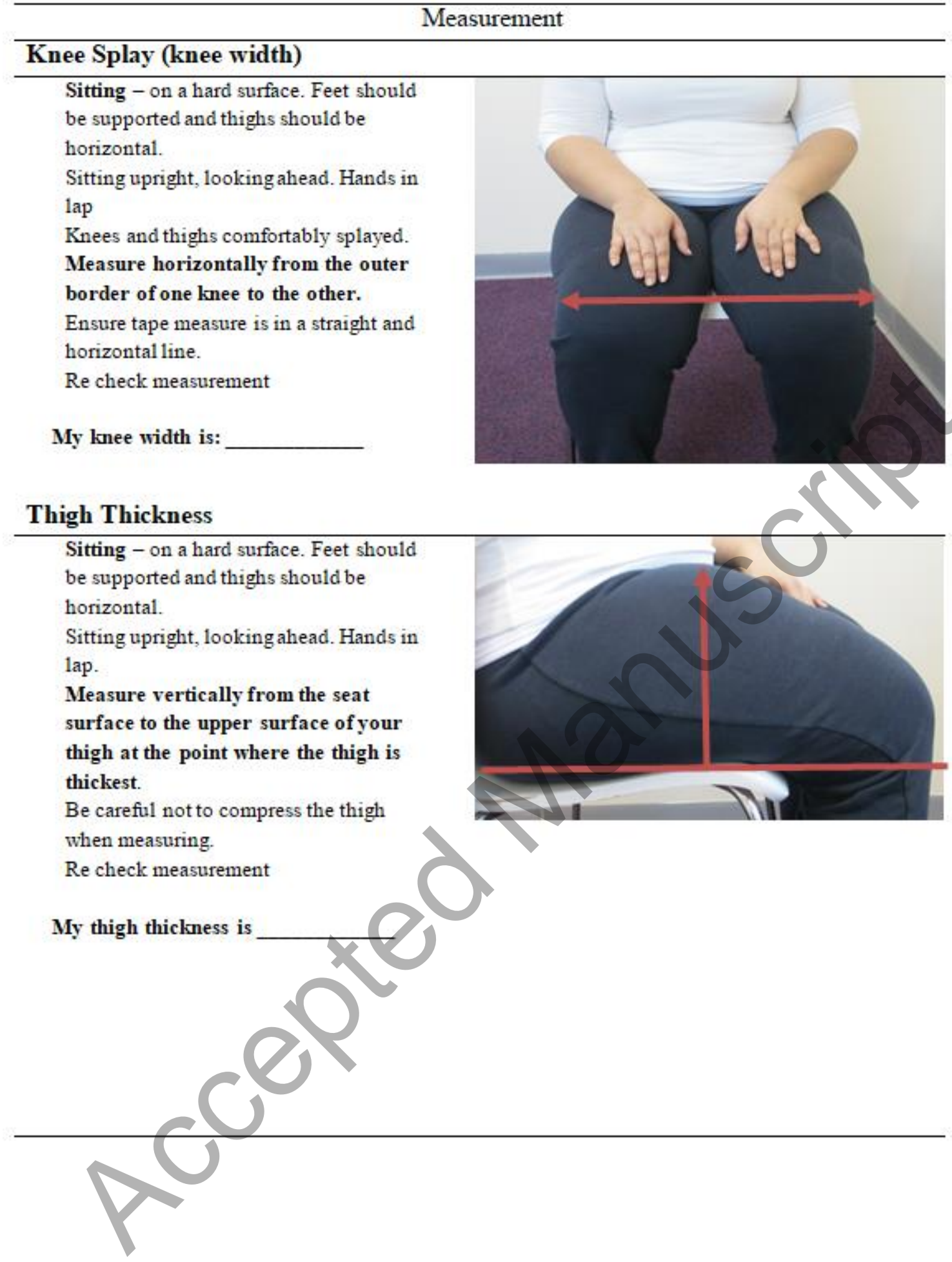

